\title{
EFFECTIVENESS OF PSYCHO EDUCATION TREATMENT FOR REDUCTION OF POSTPARTUM DEPRESSION: A SYSTEMATIC REVIEW
}

\author{
Silvie Arie Kartika, Tri Krianto \\ Masters in Public Health, Faculty of Public Health, Universitas Indonesia
}

\begin{abstract}
Backgroud: Postpartum depression is one of the emotional disorders that results from the failure of the psychological process of postpartum adaptation. Postpartum depression endangers maternal health and affects social relationships, and negatively impacts the development of the baby. If left untreated adequately, postpartum depression may cause more serious psychiatric disorders, such as bipolar disorder, schizophrenia, and even a thought of killing own infants. Previous primary studies reported that therapeutic interventions such as Psycho education can reduce postpartum depressive symptoms. This study aimed to review systematically the effectiveness of Psycho education treatment for reduction of postpartum depression.

Subjects and Method: A systematic review was carried out with PRISMA model. This systematic review was conducted by searching published articles from 2013 to 2019 from EBSCO database. The inclusion criteria were mothers with postpartum depression, aged 20 to 45 years, and Randomized Controlled Trial (RCT). Depression was measured by Edinburgh Postnatal Depression Scale (EPDS) and Beck Depression Inventory (BDI)-II. Exclusion criteria were journal older than 2013, mothers with acute psychosis, and a lifetime history of depression. The dependent variable was postpartum depression. The independent variable was Psycho education treatment using telephone or internet media. Based on inclusion and exclusion criteria, screening of titles and abstracts resulted in 5 articles. Results: Psycho education treatment took various forms, including (1) Telephone-Based Cognitive Behavioral Therapy; (2) The MOM (Managing Our Mood) therapy; (3) Telephone-Based Support; and (4) Internet-Delivered Cognitive Behavior Therapy. Mothers under study were satisfied with the intervention, suggesting positive effect of the intervention. The treatment was accessible and effective to reduce mild to moderate postpartum depression. However, its application was limited as it was dependent upon access and signal of internet connection.

Conclusion: Psycho education treatment using telephone or internet media suggest its effectiveness to reduce mild to moderate postpartum depression. However, its application is limited.
\end{abstract}

Keywords: Psycho education treatment, postpartum depression

\section{Correspondence:}

Silvie Arie Kartika. Masters in Public Health, Faculty of Public Health, Universitas Indonesia, Depok 16424, West Java. Email: Silvieariekartika@gmail.com Mobile: 085669551193.

\section{BACKGROUND}

Postpartum Depression (PPD) is a common disorder with high morbidity. PPD has been estimated to range from $7 \%$ to $16 \%$ (Stuart, 2012). Postpartum depression is a psychological problem experienced by the mother after 4 weeks of birth characterized by feelings of sadness, decreased mood, loss of interest in daily activities, significant increase or decrease in body weight, feeling useless or guilty, fatigue, decreased concentration and even the idea of suicide. In severe cases depression can be psychotic, with hallucinations, delusions and thoughts to kill a baby. It is known that about $20-40 \%$ of women report emotional disturbances or cognitive dysfunction in 
the postpartum period. Adjustment to become a new mother is a major change in life that presents challenges for new mothers. For some people, this common challenge is getting worse when mothers experience postpartum depression (Barr, 2008).

Based on the Centers for Disease Control and Prevention (CDC), the prevalence of postpartum depression in the United States in 2004-2005 was between $11.7 \%-20.4 \%$. If this condition is not treated properly, it can develop into postpartum psychosis. Postpartum depression can affect low-income minority women with broad long-term consequences, including loss of welfare support, household food insecurity, and sub-optimal children's health (Casey et al., 2004), as well as various developments. Delays in children, for example behavioral problems and cognitive delays in the form of poor language and lower IQ (O'Hara and McCabe, 2013).

A study by Beck (2008) in Joni et al. (2014) stated that some of the risk factors for postpartum depression identified were biological or hormonal, social support, low self-esteem, life stress, fatigue, prenatal depression, prenatal anxiety, poor marital relationships, history of depression, difficult baby temperament, status low socioeconomic status, single marital status and unplanned/unwanted pregnancy. In addition, in the study conducted by Leigh and Jeannette (2008) it states that risk factors that are strongly associated with Postnatal Depression are, a history of depression, antenatal depression, antenatal anxiety, stressful life, negative cognitive style, low self-esteem, low social support, and low income.

Various studies have been conducted in Indonesia, one of them was a study done by Zulpatin et al. (2016) which found that the majority of mothers who experience postpar- tum depression are aged 20-35 years old, although in some cases postpartum depresssion generally occurs in women $<20$ years old. In addition, there were mothers with low education, mothers who do not work, low income, maternal parity, lack of knowledge about the incidence of postpartum depression, mothers have who lack of social support.

Mothers with postpartum depression who do not get treatment can lead to Postpartum psychosis. Symptoms can appear within a few days after giving birth and include agitation, irritability, mood swings, disorientation, and irregular behavior. The mother can develop delusions about the baby or hear sounds (auditory hallucinations) that instruct her to hurt herself or the baby. For that reason, in overcoming the problem of mothers with postpartum depression can be done with the treatment given based on the severity of depression and personal choices (Ume, 2011).

One intervention that can be done for mothers with postpartum is psycho-education treatment. Psycho-education is an education or training for someone who has a psychiatric disorder, where this intervention is useful to develop and increase patient acceptance of the disease or disorder experienced by a person, increase patient participation in therapy, and the development of coping mechanisms (Reza et al., 2014). Psycho education treatment interventions are to teach cognitive and behavioral strategies to manage early maternal demands, such as challenging and modifying dysfunctional cognitive, applying problem solving skills to overcome childcare, and improving communication skills to manage interpersonal conflicts. 


\section{SUBJECTS AND METHOD}

\section{Study Design}

This study was a systematic review of relevant articles about the treatment that can be given to patients with postpartum depression. Articles were selected using PRISMA. Articles that did not meet the criteria of identification, screening, and eligibility were eliminated. Articles were accessed from EBSCO database.

\section{Inclusion and Exclusion Criteria}

Inclusion criteria were mothers with postpartum depression diagnoses using the Edinburg Postnatal Depression Scale (EPDS), Beck Depression Inventory (BDI) -II scores, postpartum mothers aged 20-45 years old, design of the study used the Randomized Control Trial (RCT) method. Exclusion Criteria were journals under 2013, mothers with acute psychosis, and a lifetime history of depression.

\section{Data Analysis}

The article was searched with the keywords "treatment" AND "depression postpartum" through the EBSCO Host search engine. The results obtained were 1,916 documents. Screening based on publication (2013-2019) were 914, written in English and free full text were 411.

Articles were searched based on the title and abstract. The selected articles were screened according the inclusion and exclusion criteria, resulting in 5 articles for further review. Data extraction and data analysis were carried out by the author. The selection process is presented in Figure 1. The results of the review were arranged in the form of narration.
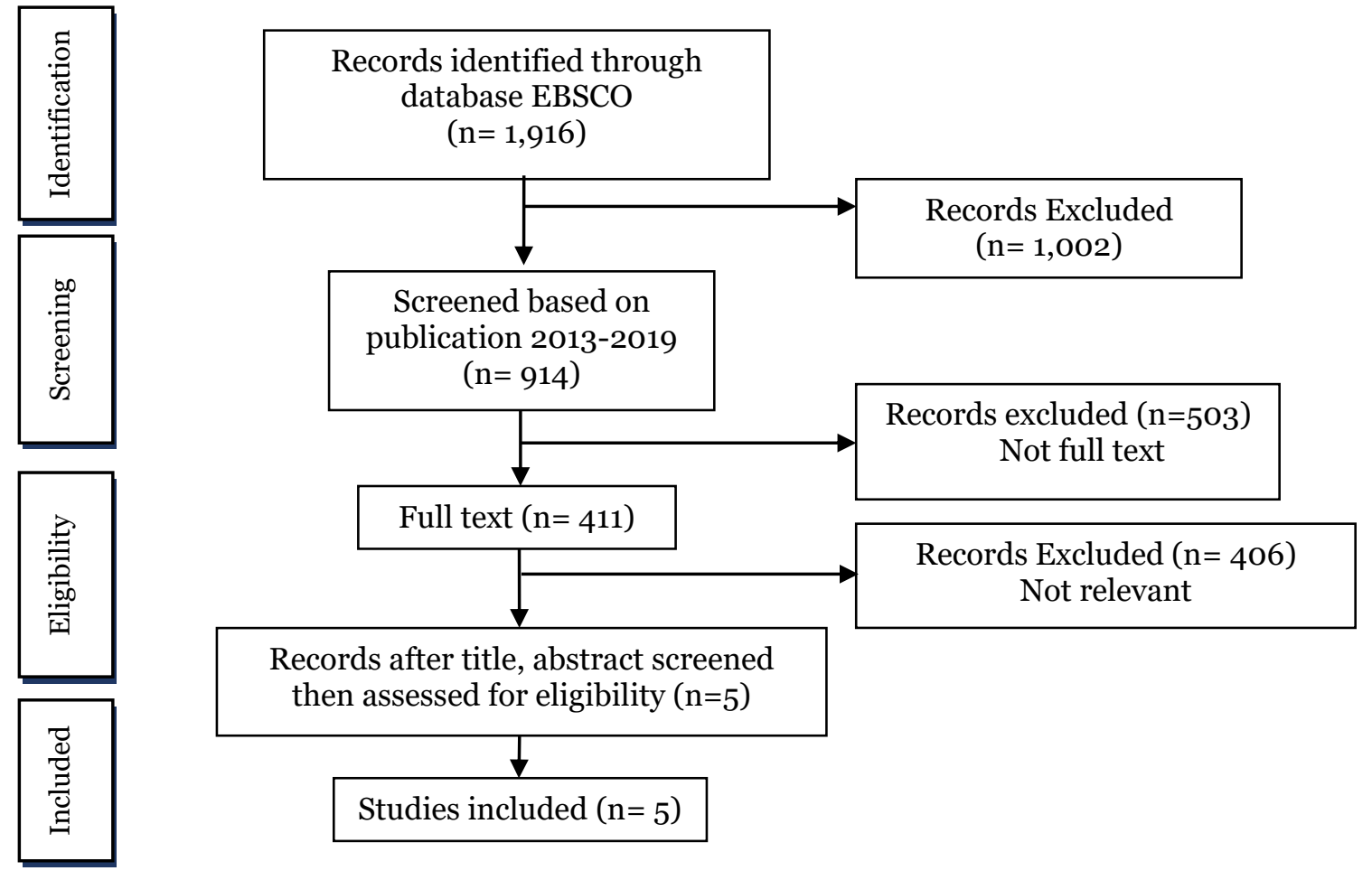

\section{Figure 1. PRISMA Flow Diagram}




\begin{abstract}
RESULTS
The selected 5 articles reported Randomized Control Trial results from Hong Kong, Canada, Iran, and the United States. These studies showed that psycho education treatment provided by telephone and internet was effective in reducing postpartum depression, particullary at mild-moderate levels.
\end{abstract}

\section{Intervention Characteristics}

Telephone-Based Cognitive Behavioral Therapy, The MOM (Managing Our Mood) therapy, Telephone-Based Support, Therapy assist Internet-Delivered Cognitive Behavior Therapy, Behavioral education is a variety of intervention approaches from a form of psycho education treatment where using media such as the telephone or the internet as a tool. Analysis was performed based on clinical characteristics, sample size, control type, intervention format and session content (see table 1.) Session content was mostly about postpartum depression education, motivation and behavior change, communication skills, building partner relationships, selfcare steps, problem solving.

\section{Methodological Quality}

Table 1. Methodology quality

\begin{tabular}{|c|c|c|c|c|c|c|c|c|c|}
\hline Study & $\begin{array}{l}\text { Sample } \\
\text { Chart }\end{array}$ & $\begin{array}{l}\text { Sample } \\
\text { Power }\end{array}$ & ITT & Control & $\begin{array}{l}\text { Assess } \\
\text { Point }\end{array}$ & $\begin{array}{l}\text { Blind } \\
\text { Assess }\end{array}$ & $\begin{array}{l}\text { Drop } \\
\text { Out }\end{array}$ & $\begin{array}{l}\text { Loss } \\
\text { to } \\
\text { FU }\end{array}$ & Exclude \\
\hline $\begin{array}{l}\text { Ngai et al. } \\
\text { (2017) }\end{array}$ & + & + & + & + & + & + & + & + & + \\
\hline $\begin{array}{l}\text { Wozney } \\
\text { et al. } \\
(2017)\end{array}$ & + & + & + & + & + & + & - & + & + \\
\hline $\begin{array}{l}\text { Milani et } \\
\text { al. (2015) }\end{array}$ & + & - & + & + & + & + & - & + & - \\
\hline $\begin{array}{l}\text { Pugh et } \\
\text { al. (2016) }\end{array}$ & + & + & + & + & + & + & + & + & - \\
\hline $\begin{array}{l}\text { Howell et } \\
\text { al. (2013) }\end{array}$ & + & + & + & + & + & + & + & + & + \\
\hline
\end{tabular}

Sign "+”Yes; “-“ No.
The methodological quality of the study including assessing treatment interventions to reduce Post-Partum Depression can be seen in Table 2. Of the 5 studies providing socio demographic information to characterize participants, 4 studies reported conducting strength analyzes to determine sample size, and intention-to-treat analysis was mentioned in 5 studies.

The effects of potential confounders (socio demographic characteristics, antidepressant treatment) were controlled in the analysis in 5 studies, in addition, the assessment points and blind assessment in this study were also carried out. Then 3 studies explained that there were participants who dropped out, 5 studies had loss to follow up the incidents, 3 studies reported exclusions in this study.

The sample chart illustrated the characteristics of the sample, Sample power reports strength analysis, intention-to-treat (ITT) analysis, control (confounding control report in data analysis), Assess point, Blind assessment, Drop Out, Loss to follow up, exclude (participants who get other treatments ex: get anti-depressant, psychiatrist care). 


\section{Intervention outcomes}

The results of a study conducted by 3 hospitals in Hong Kong of mothers over the age of 18 years old, EPDS score above 9, namely by providing cognitive behavioral therapy-based psycho education treatment by telephone for 5 weeks was effective in reducing depression scores and increasing health related quality of life (HRQoL) in mothers suffering from postpartum depression, mean difference of $1.76(95 \% \mathrm{CI}=0.19$ to $3.33 ; \mathrm{p}=0.028)$ in addition, mothers were also able to overcome emotional problems and the ability of problem solving also increased.

A study conducted in Canada reported that symptoms of postpartum depression decreased more among participants in the TAICBT group (average reduction of 6.24 points in EPDS) compared to participants in the control group (mean reduction of 2.42 points in EPDS), where ICBT participants showed a decrease in postpartum anxiety, general stress, and parental pressure, and an increase in psychological and environmental quality when compared with control participants. A study conducted in Iran showed that after psycho education treatment, a comparison of depression reduction between the intervention group (4.7 score) and control (2.5 score) showed a more significant decrease in the intervention group than the control group. A study in the USA showed the results of follow-up on the intervention 6 months postpartum. This intervention succeeded in reducing depressive symptoms among black postpartum mothers and Latina. Postpartum depression symptoms affect women of all racial/ethnic and socioeconomic background.
They are more burdensome for low income women with skin tone who lack of resources and access to care.

\section{DISCUSSION}

Psycho-education treatment has a positive effect on mothers with postpartum depression, especially at mild-moderate levels, where mothers who have been given treatment felt changes in themselves such as being able to deal with emotional problems, parental pressure, being able to care for their babies, mothers have good communication skills, and has been able to do coping problems.

In addition, mothers were also satisfied with the treatment that has been given, so that the quality of life-related index of health increased, EPDS and BDI-II scores have decreased, which mean that the psychological quality of the mother was already better.

This was in accordance with the theory that psycho-education is health education that can be given to patients with mental disorders, can be in the form of depression, anxiety and schizophrenia.

This psycho-education therapy can be in the form of passive psycho-education such as providing information with leaflets or via e-mail or website and can also be in the form of active psycho-education in the form of counseling or providing health education individually or in groups by teaching cognitive and behavioral strategies to manage early maternal demands, such as challenging and modifying cognitive dysfunctional, applying problem solving skills to overcome childcare, and improving communication skills to manage interpersonal conflicts. 
Table 2. Reviewed articles

\begin{tabular}{|c|c|c|c|c|c|c|c|c|}
\hline No. & Location & $\begin{array}{c}\text { Sample } \\
\text { Size }\end{array}$ & $\begin{array}{c}\text { Intervention } \\
\text { approach }\end{array}$ & $\begin{array}{l}\text { Design } \\
\text { Study }\end{array}$ & $\begin{array}{l}\text { Control } \\
\text { Type }\end{array}$ & $\begin{array}{l}\text { Intervention } \\
\text { format }\end{array}$ & Session & Conclusion \\
\hline 1. & Hongkong & 197 & T-CBT & RCT & TAU & $\begin{array}{l}\text { Individuals } \\
\text { and groups }\end{array}$ & $\begin{array}{c}5-8 \\
\text { sessions }\end{array}$ & $\begin{array}{l}\text { These findings highlight the importance } \\
\text { of integrating psychological care into } \\
\text { perinatal care, and in particular T-CBT } \\
\text { as a promising intervention to improve } \\
\text { Health-related quality of life. }\end{array}$ \\
\hline 2. & $\begin{array}{l}\text { Nova } \\
\text { Scoatia } \\
\text { (Canada) }\end{array}$ & 62 & MOM & $\mathrm{RCT}$ & TAU & $\begin{array}{l}\text { Individuals } \\
\text { and groups }\end{array}$ & $\begin{array}{c}12 \\
\text { sessions }\end{array}$ & $\begin{array}{l}\text { The MOM program can function as an } \\
\text { effective treatment option for mothers } \\
\text { who experience significant or marginali- } \\
\text { zed stigma and lack of resources in their } \\
\text { local community. }\end{array}$ \\
\hline 3. & Iran & 54 & TBS & RCT & $\begin{array}{c}\text { No } \\
\text { intervention } \\
\text { was carried } \\
\text { out }\end{array}$ & $\begin{array}{l}\text { Individuals } \\
\text { and groups }\end{array}$ & $\begin{array}{c}12-18 \\
\text { sessions }\end{array}$ & $\begin{array}{l}\text { In this study, support/education } \\
\text { through telephone-based support was } \\
\text { effective in reducing PPD and was bene- } \\
\text { ficial for women with mild and mode- } \\
\text { rate PPD symptoms. }\end{array}$ \\
\hline 4. & Canada & 50 & TA-ICBT & RCT & WL & $\begin{array}{l}\text { Individuals } \\
\text { and groups }\end{array}$ & $\begin{array}{c}10 \\
\text { sessions }\end{array}$ & $\begin{array}{l}\text { TA-ICBT is effective in reducing PPD } \\
\text { symptoms, parental stress, and impro- } \\
\text { ving psychological and environmental } \\
\text { quality of life. But it requires an assess- } \\
\text { ment of cost-effectiveness. }\end{array}$ \\
\hline 5. & USA & 540 & $\begin{array}{l}\text { Behavioral } \\
\text { Education }\end{array}$ & $\mathrm{RCT}$ & TAU & $\begin{array}{l}\text { Individuals } \\
\text { and groups }\end{array}$ & $\begin{array}{c}5 \\
\text { sessions }\end{array}$ & $\begin{array}{l}\text { This study developed a behavioral edu- } \\
\text { cation intervention that succeeded in re- } \\
\text { ducing postpartum depression symp- } \\
\text { toms among low-income and Latina } \\
\text { black women. }\end{array}$ \\
\hline
\end{tabular}

T-CBT (Telephone-Based Cognitive Behavioral Therapy), MOM (Managing Our Mood) cognitive-behavioral, TBS (Telephone-Based Support), TA-ICBT (Therapist Assisted, Internet-Delivered Cognitive Behavior Therapy), RCT (Randomized Control Trial, TAU (Treatment As Usual), WL (Waiting List).

The $6^{\text {th }}$ International Conference on Public Health Best Western Premier Hotel, Solo, Indonesia, October 23-24, $2019 \mid 205$

https://doi.org/10.26911/the6thicph-FP.03.04 
Nowadays, where the world has entered the era of technology, mothers indeed have telephone and internet access. This treatment certainly provide convenience for mothers because they were not only obtained information about PPD through leaflets, or handbooks that contained videos and exercises that can opened in their respective homes, but mothers were also given coaching and support via telephone and internet, mothers were also given the opportunity to consult via email. The information provided also include knowledge about PPD, motivating and educating behavior change, recognizing negative thinking patterns, learning relaxation strategies, building relationships and self-care.

In line with a study by Soep (2009) the current study found that psycho-education was effective in reducing depression in postpartum mothers. This study was conducted among primiparous working mothers aged $\geq 20$ years.

Psycho-education treatment using telephone or internet media showed its effectiveness in reducing mild to moderate postpartum depression. However, its application was still limited and also in the process, the support from the husband and family of the patient to overcome maternal postpartum depression was highly necessary.

\section{REFERENCES}

Leigh B, Jeannette M (2008). Risk factors for antenatal depression, postnatal depression and parenting stress. BMC Psychiatry, 8 (24): 1-12. doi: 10.1186/1471244X-8-24

Casey P, Goolsby S, Berkowitz C, Frank D, Cook J, Cutts D, et al. (2004). Maternal depression, changing public assistance, food security, and child health status.
Pediatrics, 113: 298-304. doi: 10.1542/peds.113.2.298.

Howell EA, Deren SB, Balbierz A, Loudon H, Mora PA, Zlotnick C, et al. (2014). An intervention to reduce postpartum depressive symptoms : A randomized controlled trial. Arch Womens Ment Health, 17 (1): 57-63. doi: 10.1007/so0737-013-0381-8.

Joni LBA, Nicole L (2014). New mothers and postpartum depression: a narrative review of peer support intervention studies. Health and Social Care in the Community 23 (4): 337-348. doi: 10.1111/hsc.12125

Milani HS, Azargashb E (2015). Effect of telephone-based support on postpartum depression : A randomized controlled trial. Int J Fertil Steril, 9 (2): 247253. doi: 10.22074/ijfs.2015.4246

Ngai FW, Wong PW, Chung KF, Leung KY (2017). The effect of a telephone-based cognitive behavioral therapy on quality of life: A randomized controlled trial. Arch Womens Ment Health, 20 (3): 421-426. doi: 10.1007/s00737-017-0722-0.

O’Hara MW, McCabe JE (2013). Postpartum depression: Current status and future directions. Annu Rev Clin Psychol, 2013 (9): 379-407. doi: 10.1146/annurev-clinpsy-050212-185612

Pugh NE, Hadjistavropoulos HD, Dirkse D (2016). A randomised controlled trial of therapist- assisted, internet-delivered cognitive behavior therapy for women with maternal depression. PLoS One, 11 (3): 1-14. doi: 10.1371/journal.pone.o149186

Reza M, Bordbar F, Faridhosseini F (2014). Psycho education for bipolar mood disorder. https://doi.org/10.5772/31- 
698

Stuart S (2012). Interpersonal psychotherapy for postpartum depression. Clin Psychol Psychother, 19 (2): 134-140. https://doi.org/10.1002/cpp.1778

Ume (2011). Beyond the "baby blues." Newsletter. Retrieved from https://www.health.harvard.edu/newsletter_ar ticle/beyond-the-baby-blues

Wozney L, Olthius J, Lingley PP, McGrath PJ, Chaplin W, Elgar F, et al. (2017). Strongest families $^{\text {tm }}$ managing our mood (MOM): A randomized controlled trial of a distance intervention for women with postpartum depression. Arch Womens Ment Health, 20(4): 525-537. doi: 10.1007/s00737-017-0732-y. Zulpatin N, Arief W, Endang WG (2016). Determinants factors of postpartum depression in East Lombok. Bulletin of Health System Reserach. 20 (3): 8995. doi: 10.22435/hsr.v20i3.6137.89-95 